\title{
A HIGH VOLTAGE, HIGH PERFORMANCE THICK FILM RESISTOR SYSTEM
}

\author{
SIDNEY J. STEIN, CORNELIUS HUANG and ALLAN S. GELB \\ Electro-Science Laboratories, Inc., Pennsauken, New Jersey 08110, U.S.A.
}

(Received June 1, 1977)

\begin{abstract}
This paper describes a new series of thick film resistors based on a ruthenium-compound semiconducting phase, dispersed in a carefully selected and compatible glassy matrix. Analysis of the electrical properties of these resistors indicates that the conducting networks present in the structure include ohmic, non-ohmic and insulating barriers.

Experimental results on the resistors are discussed in terms of resistivity and TCR vs. firing parameters. The effect of termination materials and resistor geometry, voltage coefficient of resistance, power loading and high voltage properties are also discussed.
\end{abstract}

\section{INTRODUCTION}

The complexity of behavior of thick film resistor systems has been the subject of extensive investigations for many years. Electrical properties of such resistors depend not only on their ingredient materials but also on the various processes employed in combining these materials and in fabricating the finished resistors. Various investigators have sought to explain the factors contributing to such properties as sheet resistance, temperature coefficient of resistance, ohmic and non-ohmic behavior, thermal stability and related properties. Many models proposed as a means of predicting and correlating resistor properties to ingredient properties fall short when applied broadly to different systems or even to different dilution points of a blending curve for a simple compositional system.

Thick film resistor pastes in their simplest form consist of conducting and insulating powders dispersed in a vehicle. After firing, a continuous matrix of the glass insulator is formed, which contains within it a dispersion of the conducting particles. Maxwell treated such a model theoretically in 1881 and although subsequently refined by others ${ }^{1-6}$ the model did not adequately predict observed resistivities. Consideration of the microstructures of such systems is essential for understanding their behavior. The conducting particles are assumed to be arranged in continuous chains of micro and macro networks, depending on the volume fraction of conductive material present. Scarisbrick ${ }^{7}$ developed models, involving as two extremes, the probabilities that the conducting particles are either randomly distributed or exist in completely ordered chain structures. $\mathrm{He}$ assumed no long range order but rather that nearest neighbor effects determined properties on a micro scale. Predictions of bulk properties were made by statistically averaging possible individual situations.

R. W. Vest and co-workers ${ }^{8}$ in an extensive experimental and theoretical study program investigated the conduction mechanisms and identified eight microstructure and conductive network processes which could contribute to final electrical properties of thick film resistors. These included glass sintering, spreading and densification as well as conductive particle sintering, ripening and structural microrearrangement. Ten properties of the ingredient materials were listed as contributing to the kinetics of the fabrication processes. The authors developed kinetic equations which interrelated the eight processes and the ten material properties and showed that network resistivity and TCR are extremely complex and depend on all of these interactions.

One of the problems requiring explanation is why the TCR of thick film resistors is usually less than $\pm 200 \mathrm{ppm} /{ }^{\circ} \mathrm{C}$, although they consist mainly of conducting phases which in bulk have large positive TCR's (over $4000 \mathrm{ppm} /{ }^{\circ} \mathrm{C}$ for $\mathrm{RuO}_{2}, \mathrm{IrO}_{2}$ and compounds such as bismuth ruthenate). The glasses have even larger but negative TCR's and their resistivities show an exponential dependence on temperature. The explanation offered is based on 
the concept of varying contact resistance between adjacent conducting particles.

$\mathrm{RuO}_{2}$ particles develop a neck structure as they sinter together during firing. The firing times and temperatures used in processing result in thick films which do not achieve equilibrium conditions and result in layers containing a wide spectrum of neck diameters. These necked contacts may grow to be as large as the original starting particles (sintered contacts) or in the other extreme have no physical contact and are separated by glass particles (nonsintered contacts). Sintered contacts are largely temperature independent. Non-sintered ones have an exponential temperature dependence and may involve a variety of transport mechanisms.

G. E. Pike et al. ${ }^{9,1} 0$ suggested that the conduction mechanism involved "dirty" interparticle tunnel junctions. The authors explained both the temporary change of resistance and the permanent change of resistance observed when applying voltage stresses in terms of combinations of non-tunnelling barriers and tunnelling barriers. The temporary change of resistance (VCR) is believed to be due to tunnelling

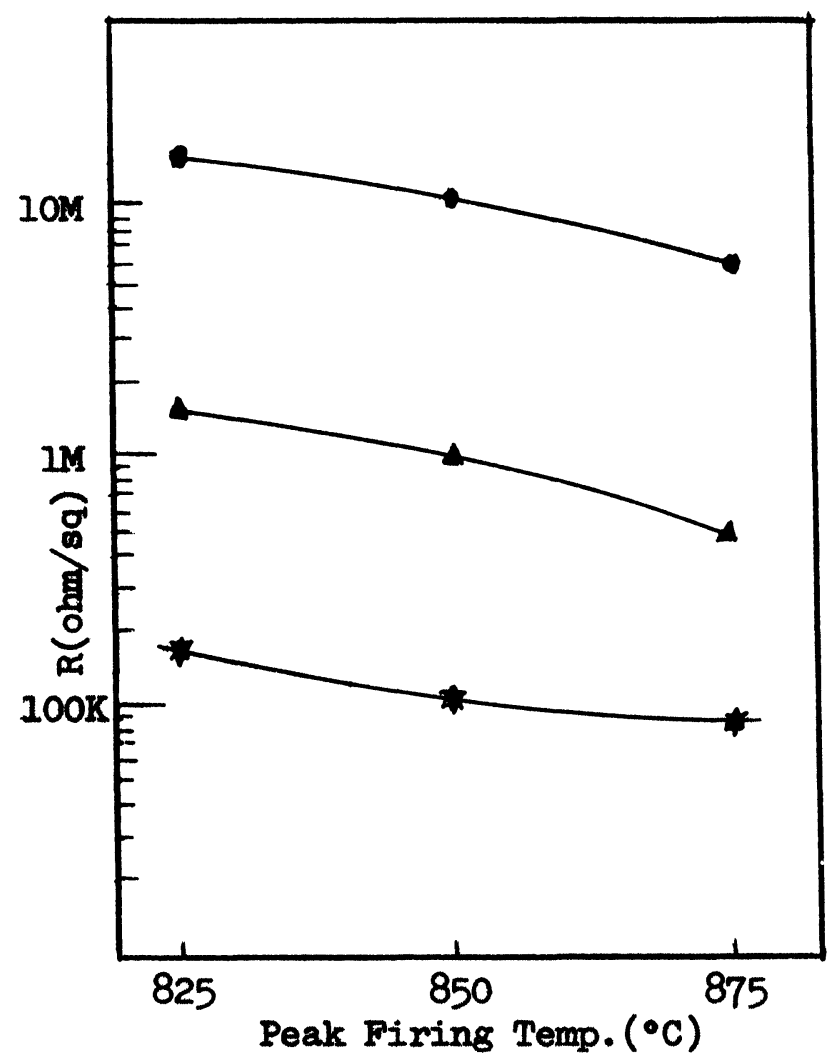

FIGURE 1 Sheet resistivity, $R$ vs. firing temperature. barriers where the electron transport is proportional to the voltage. When the outside influences, in this case voltage, are removed, recovery occurs. However, permanent resistance changes due to $\mathrm{DC}$ high voltage or to high voltage pulses are due to voltage breakdown of the non-tunnelling barrier into a tunnelling barrier. Such changes of resistance are, therefore, irreversible. Based on this assumption, the glass matrix in a thick film resistor system will play a dominant role in the high voltage behavior, particularly in very high resistivities (1 Mohm to $10 \mathrm{Mohm}$ per square). Voltage breakdown effects in thick film resistors have also been discussed by other authors, ${ }^{1-15}$ for a variety of resistor compositions. The desirability of minimizing the voltage sensitive effects of non-tunnelling barriers by the employment of voltage breakdown resistant materials, semiconductor additives, or thin segregated layers of conducting particles has been observed. Some of these approaches may have improved voltage properties at the expense of harming other properties.

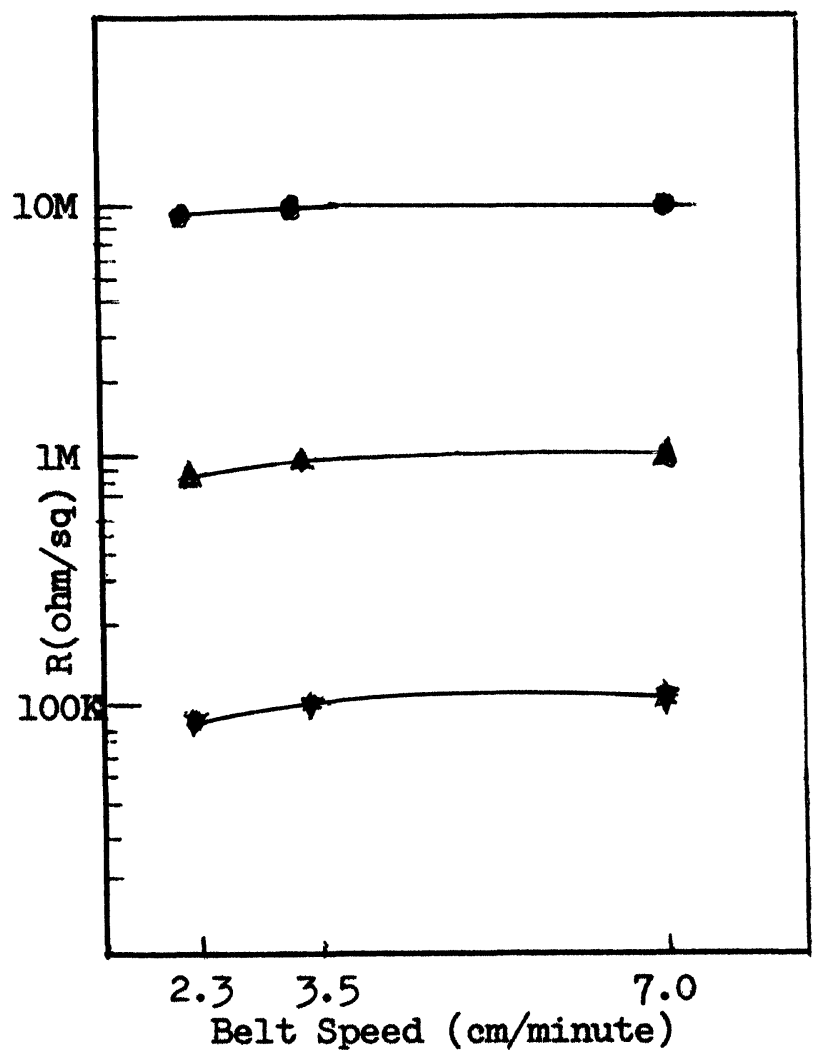

FIGURE 2 Sheet resistivity, $R$ vs. belt speed. 


\section{DISCUSSION}

A number of resistor systems have been developed which exhibited ease of processing, small TCR's and greatest stability in the mid-ranges of sheet resistivity between 100 and $100,000 \mathrm{ohm}$ per square. Problems were found to be most prevalent at the high resistivity end of the conductor-glass dilution curves. As the volume concentration of the conductive particles is decreased, resistivity increases rapidly and TCR shifts to negative values. Resistivities of $0.1 \mathrm{Mohm}$ to $10 \mathrm{Mohm}$ per square fall on the increasingly steep slope of the dilution curve. This causes greater sensitivity to firing conditions, resistor geometry, and metallurgy of conductors used for terminations. Voltage coefficients of resistivity increase as does sensitivity to various forms of thermal, voltage and thermomechanical stresses. The work described in this paper discusses the ESL 2700 Series system of resistors for high resistivity and high voltage applications. This Series is a ruthenium-based system designed to fire at peak temperatures of $850^{\circ} \mathrm{C}$ for 10 minutes in an overall

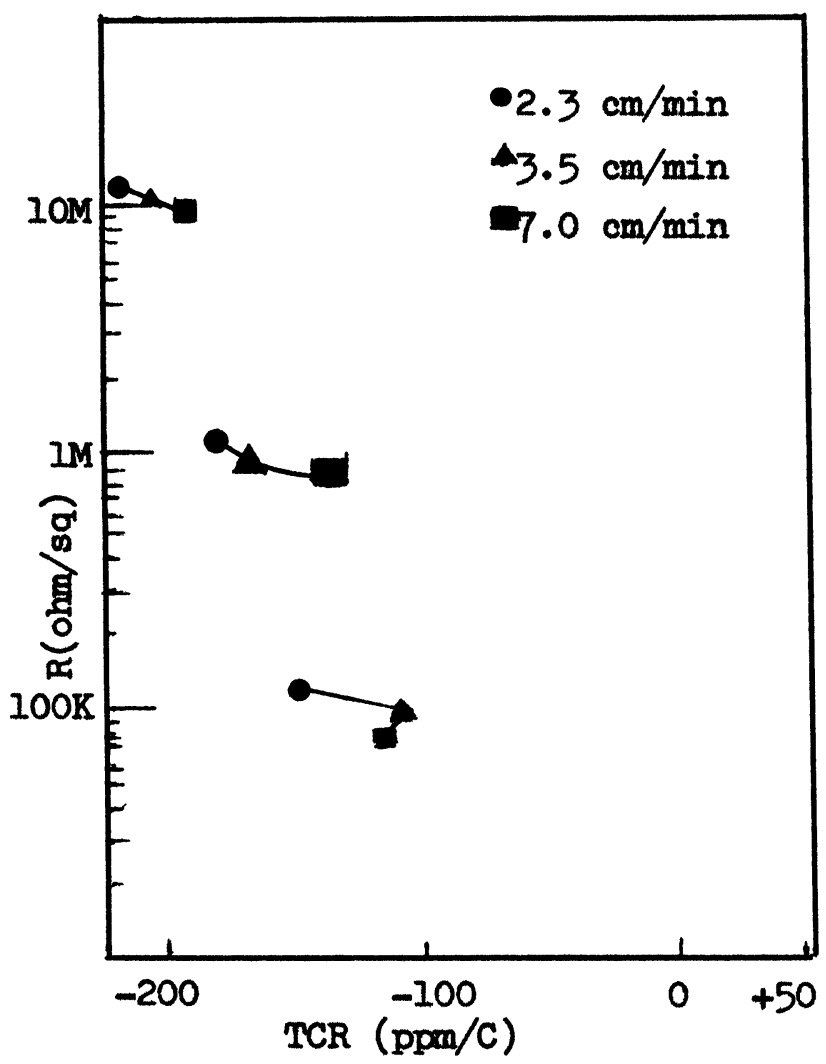

FIGURE 3 Sheet resistivity, $R$ vs. TCR.
45 minute cycle in a belt furnace. It is limited to high resistivities and may be processed at the same time that other resistors of lower resistivities are being fired.

\section{RESISTIVITY AND TCR VERSUS FIRING PARAMETERS}

Figure 1 shows the resistor sensitivity to the peak firing temperatures with $9635(\mathrm{Pd} / \mathrm{Ag})$ terminations. For $100 \mathrm{kohm}$ per square (2715) resistors, varying the peak firing temperature by plus or minus $10^{\circ} \mathrm{C}$ will give a resistance variation of about $1.2 \%$ per degree $\mathrm{C}$. This means that when the firing temperature is off $\pm 5^{\circ} \mathrm{C}$, there is only about $6 \%$ deviation of $R$ value from the calibration. Firing sensitivity increases to 2 to $3 \%$ per ${ }^{\circ} \mathrm{C}$ as the resistivities increase. $5835(\mathrm{Pt} / \mathrm{Au})$ and $8835-1 \mathrm{~B}(\mathrm{Au})$ terminations have been tested and shift resistivities upwards by 10 to 25\% as compared to $\mathrm{Pd} / \mathrm{Ag}$ terminations, especially for the 2716 and 2717 compositions. $A u$ containing terminations make the firing temperature sensitivity even lower than the $P d / A g$ types.

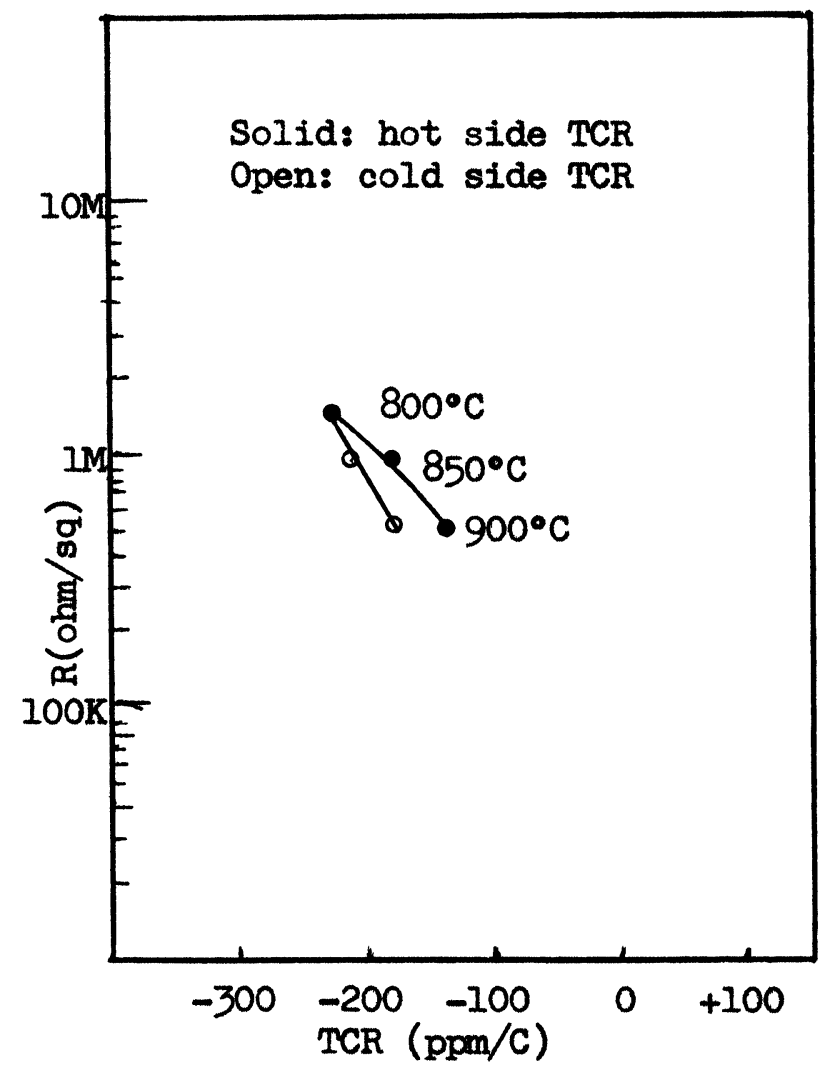

FIGURE 4 Sheet resistivity, $R$ vs. TCR for varying firing temperature. 


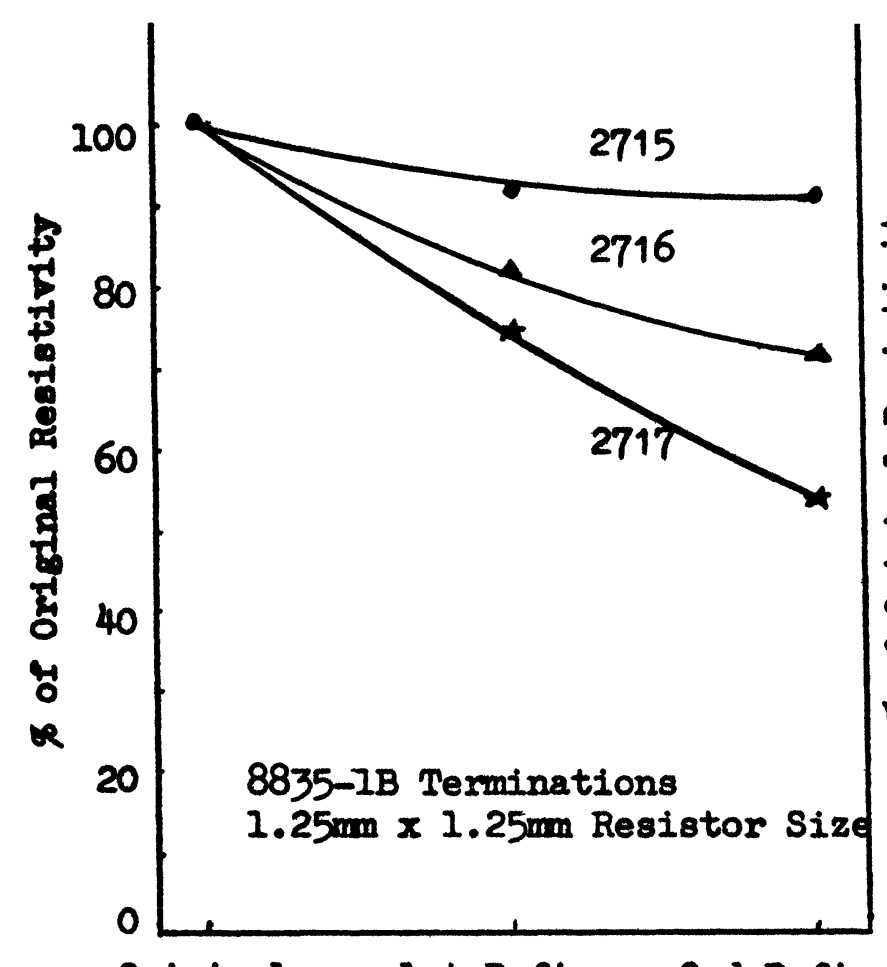

Original lst Refire 2nd Refire

(a) Effect of refire on resistivity (8835-1B terminations)

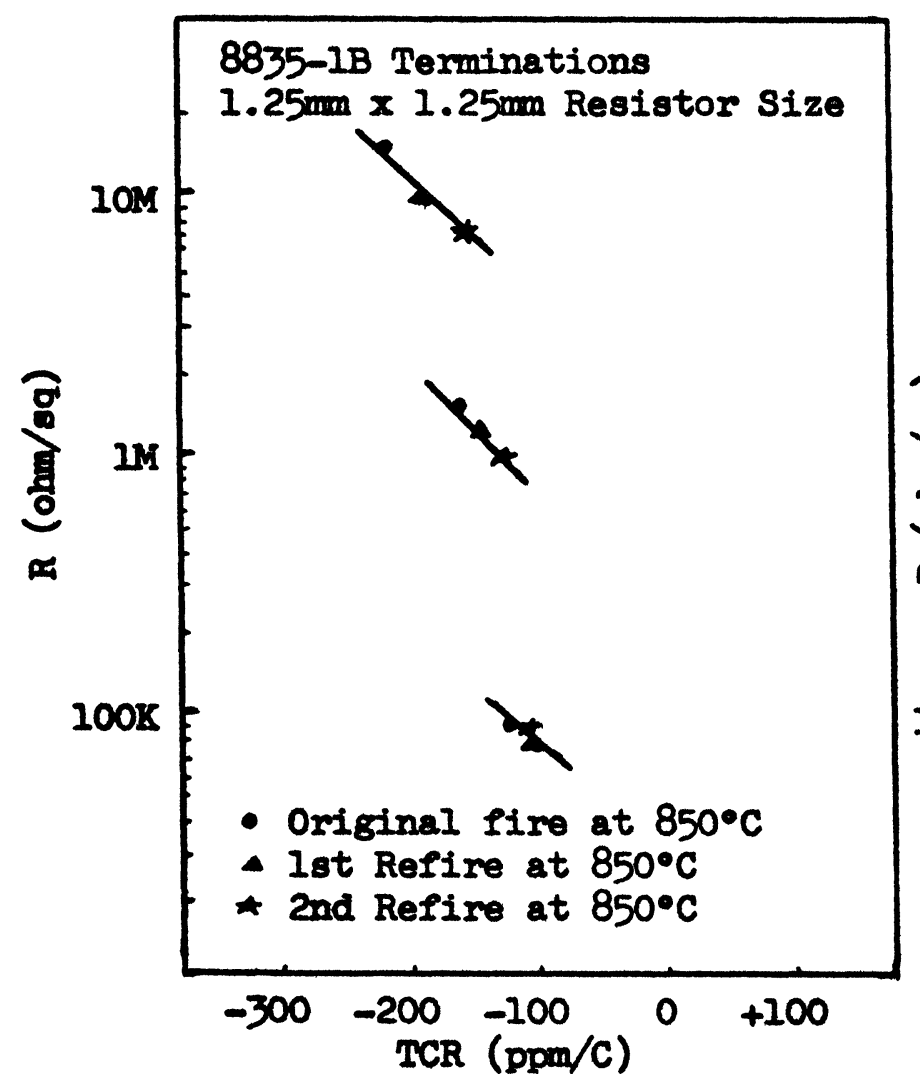

(c) Effect of refire on resistivity and TCR (8835-1B terminations)

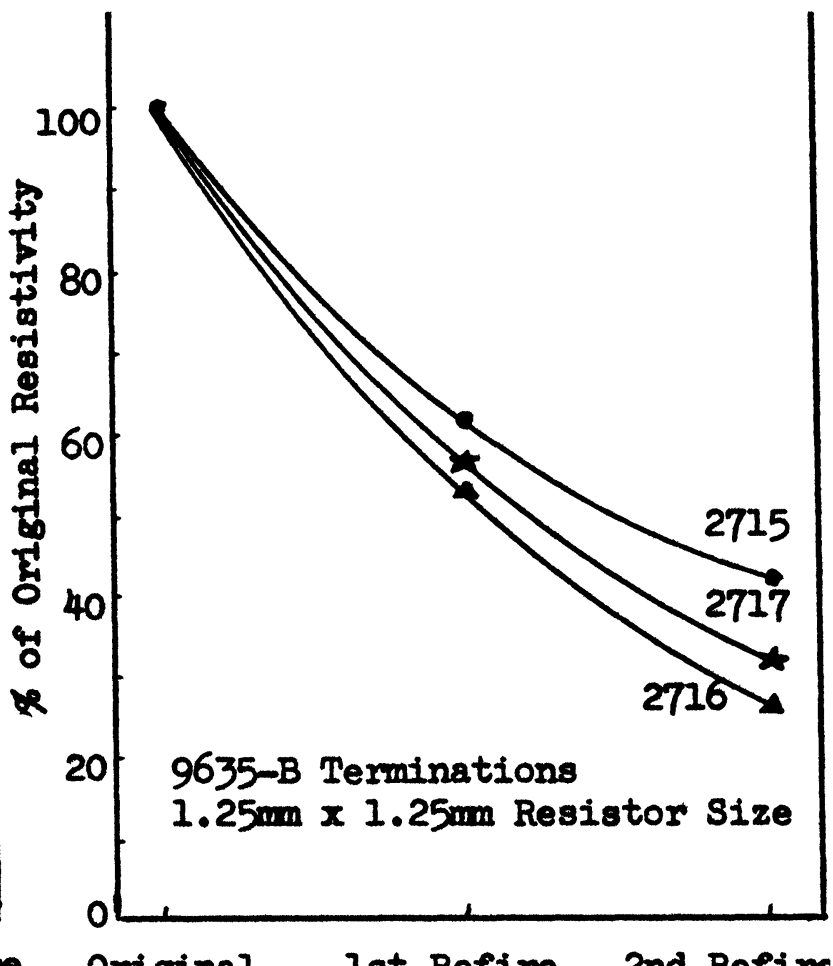

Original lst Refire 2nd Refir

(b) Effect of refire on resistivity (9635-B terminations)

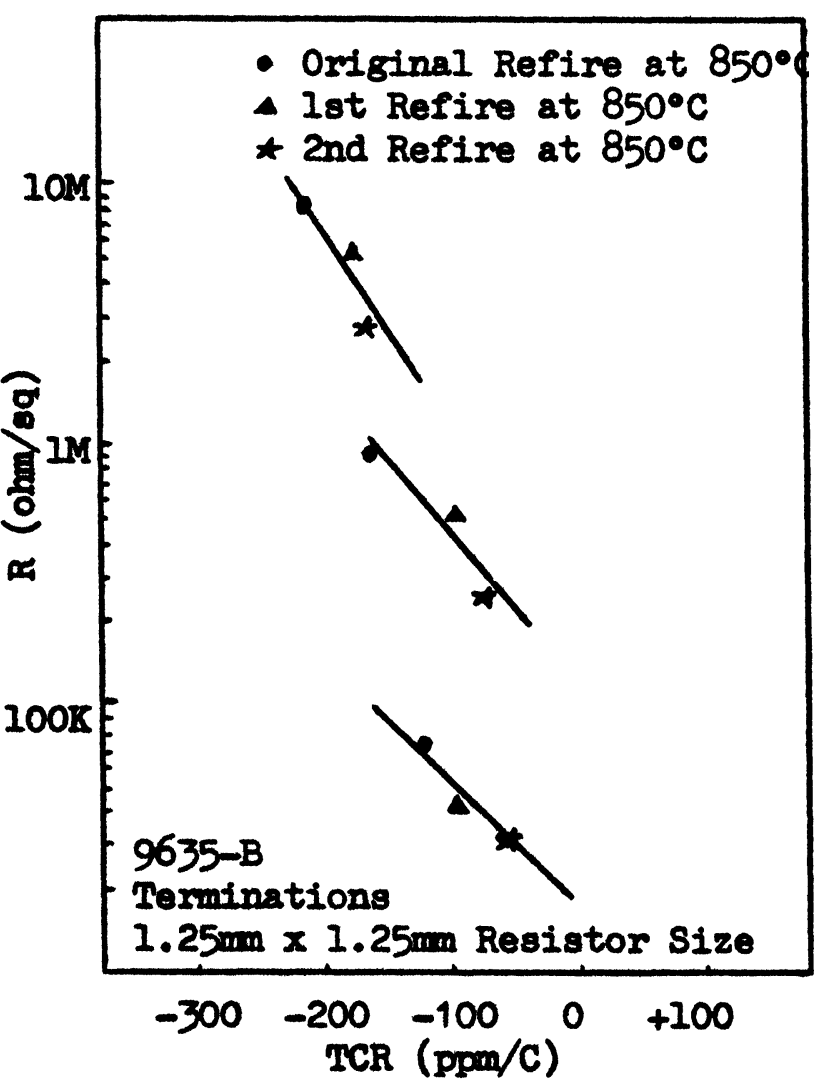

(d) Effect of refire on resistivity and TCR (9635-B terminations) 


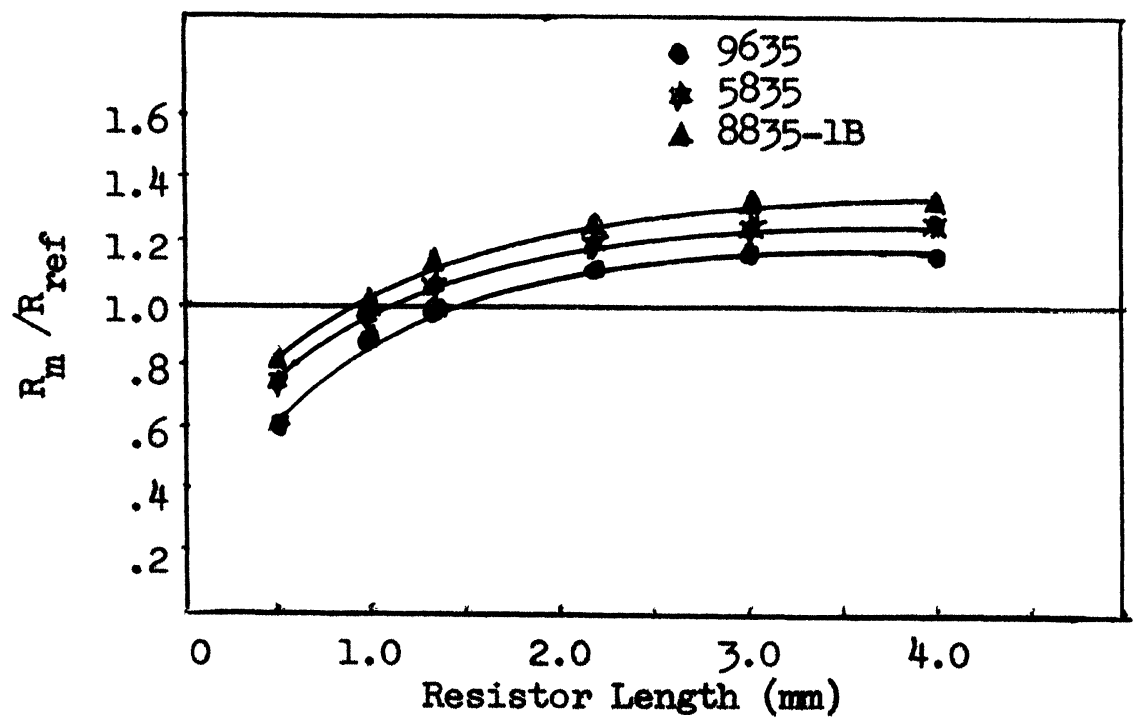

FIGURE 6 Geometry effect on resistance of 2716.

Figure 2 shows the relationship of resistance to belt speed when fired at constant temperature. For belt speeds of $23 \mathrm{~mm} / \mathrm{min}$., $35 \mathrm{~mm} / \mathrm{min}$. and $70 \mathrm{~mm} / \mathrm{min}$. there is very little variation in resistance. The $35 \mathrm{~mm} / \mathrm{min}$. speed represents the standard 45 minute overall cycle time. Basically, this resistor system is relatively insensitive to belt speed or firing time. It should be noted that faster belt speeds reduce the time at peak temperature. Figure 3 shows the TCR of the resistors fired at different belt speeds. The effects are relatively small, showing shifts about
$30 \mathrm{ppm}$ per ${ }^{\circ} \mathrm{C}$ for major changes in belt speed of three to one. Figure 4 shows the change in average TCR for -55 to $+25^{\circ} \mathrm{C}$ and +25 to $+125^{\circ} \mathrm{C}$ for 2716 (1 Mohm per square) when fired over a wide peak temperature range of 800 to $900^{\circ} \mathrm{C}$. The difference between hot to cold TCR (span) is greatest at lower firing temperatures amounting to about $50 \mathrm{ppm} /{ }^{\circ} \mathrm{C}$ at $850^{\circ} \mathrm{C}$. TCR's for the three resistivities all become more positive with increases in firing temperature. Similarly all three sheet resistivities drop with increasing peak temperatures.

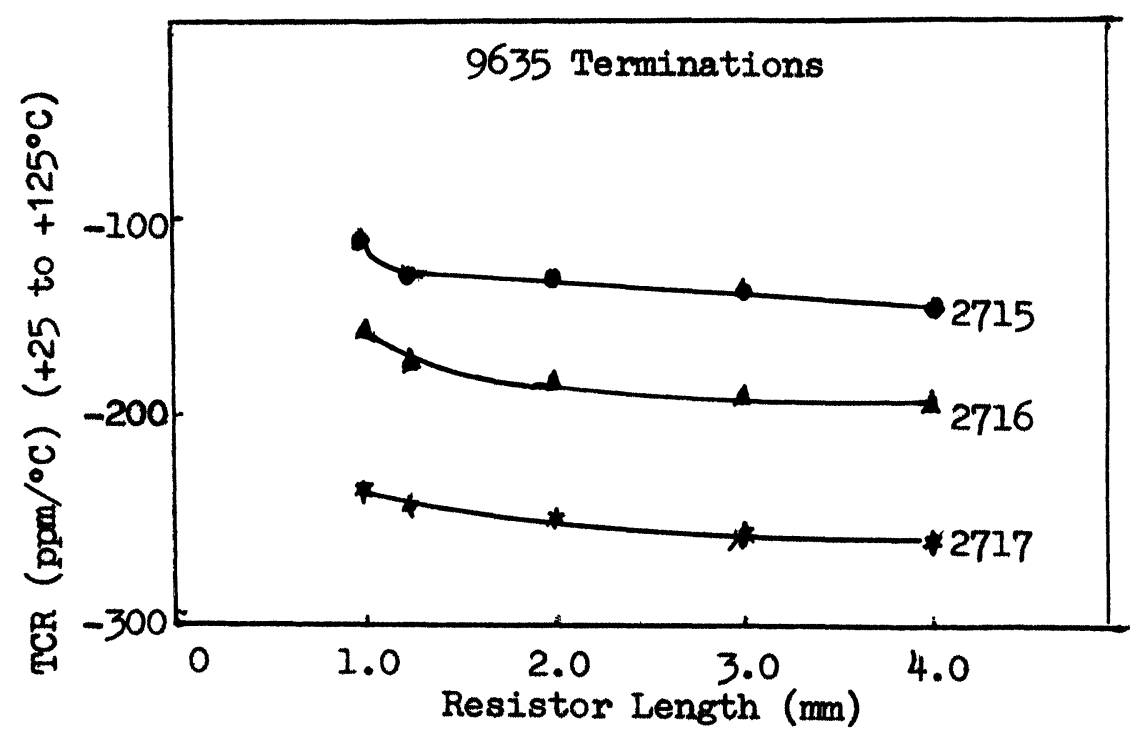

FIGURE 7 Geometry effect on TCR. 


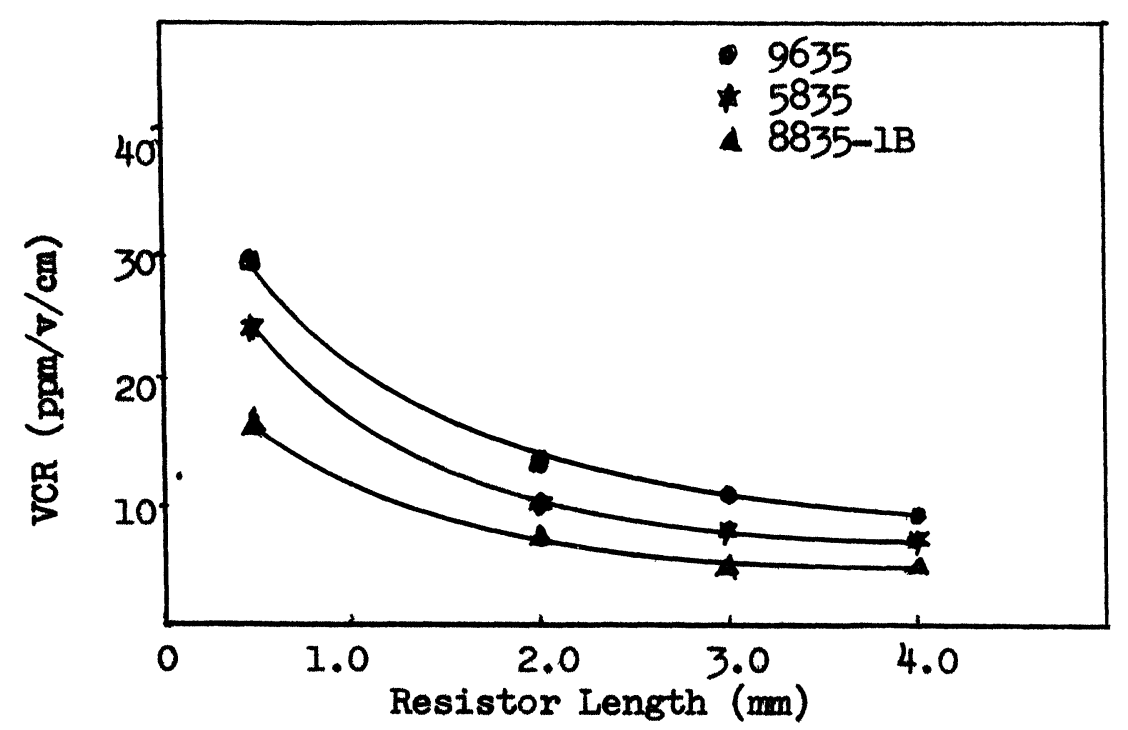

FIGURE 8 Geometry effect on VCR of 2716.

\section{REFIRING EFFECTS}

Refiring any of these resistors through the original profile will cause a decrease in resistance. Data are available showing that the resistance of resistors made with $A u$ terminations will drop less than that of those made with $P d / A g$ terminations. Among $P d / A g$ terminations, those containing more $A g$ will show larger resistance decreases. This can be related to the higher mobility of $A g$ as compared to $A u$ in diffusing into the resistor. Resistance lowering effects are most pronounced for the $10 \mathrm{Mohm}$ per square and diminish for the lower resistivities. The resistance decreases tend to stabilize upon multiple refiring particularly when $A u$ containing terminations are used. As resistance values are decreased by multiple firing with several $A u$-bearing terminations, the TCR's shift

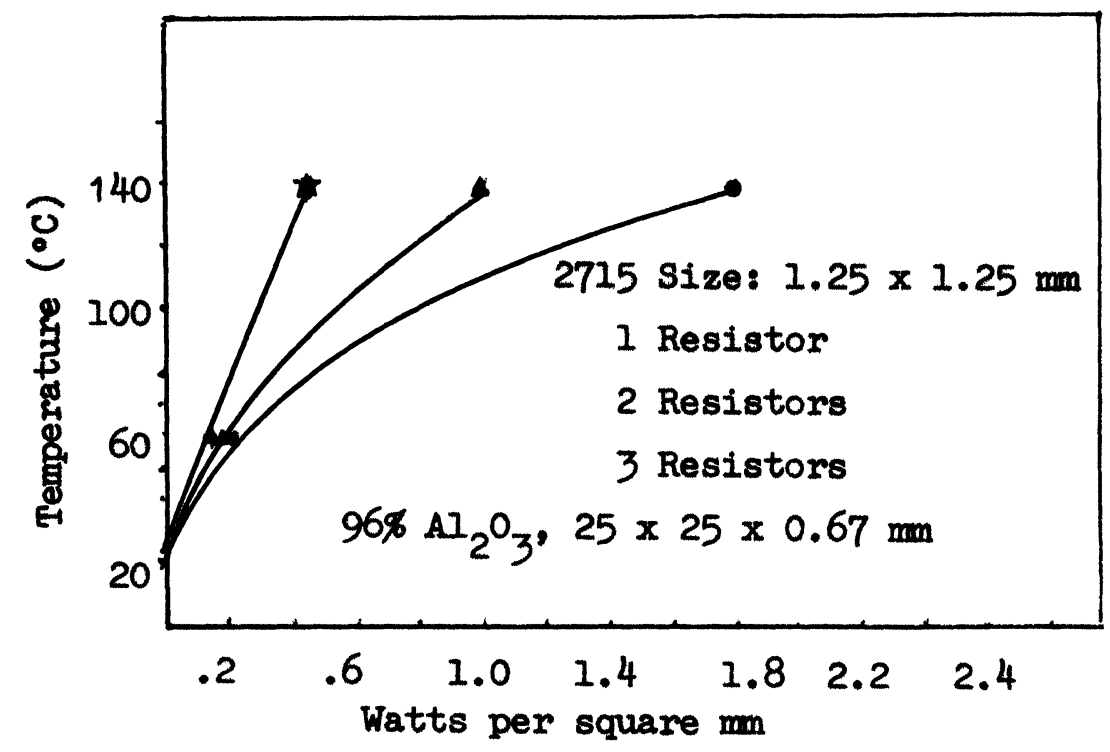

FIGURE 9 Power vs. thermal rise temperature. 
towards positive values by 10 to $30 \mathrm{ppm} /{ }^{\circ} \mathrm{C}$ for each refire. Figure 5 (a) to (d) illustrate the effects.

\section{RESISTOR GEOMETRY EFFECTS}

Figure 6 shows the effect of resistor length on relative sheet resistivity for a $1 \mathrm{Mohm}$ per square paste as a function of three termination materials: $A u, P t / A u$ and $P d / A g$. All resistivities show similarly shaped curves. The resistors were $1 \mathrm{~mm}$ wide and between 0.5 to $4.0 \mathrm{~mm}$ long. A resistor length of $1.25 \mathrm{~mm}$ using a $P d / A g$ termination was taken as the calibration reference value, $R_{\text {ref: }}$ All other measurements, $R_{m}$, are referenced to this value. The typical reduction in sheet resistivity with resistor length is shown for all conductors. However, the $P d / A g$ shows a more extensive drop for small sizes due to $A g$ diffusion. This effect is particularly severe for $0.5 \mathrm{~mm}$ long resistors and becomes more extensive for higher resistivities such as $10 \mathrm{Mohm}$ per square. We would suggest avoiding the use of resistors smaller than $1 \mathrm{~mm}$ and $P d / A g$ conductors

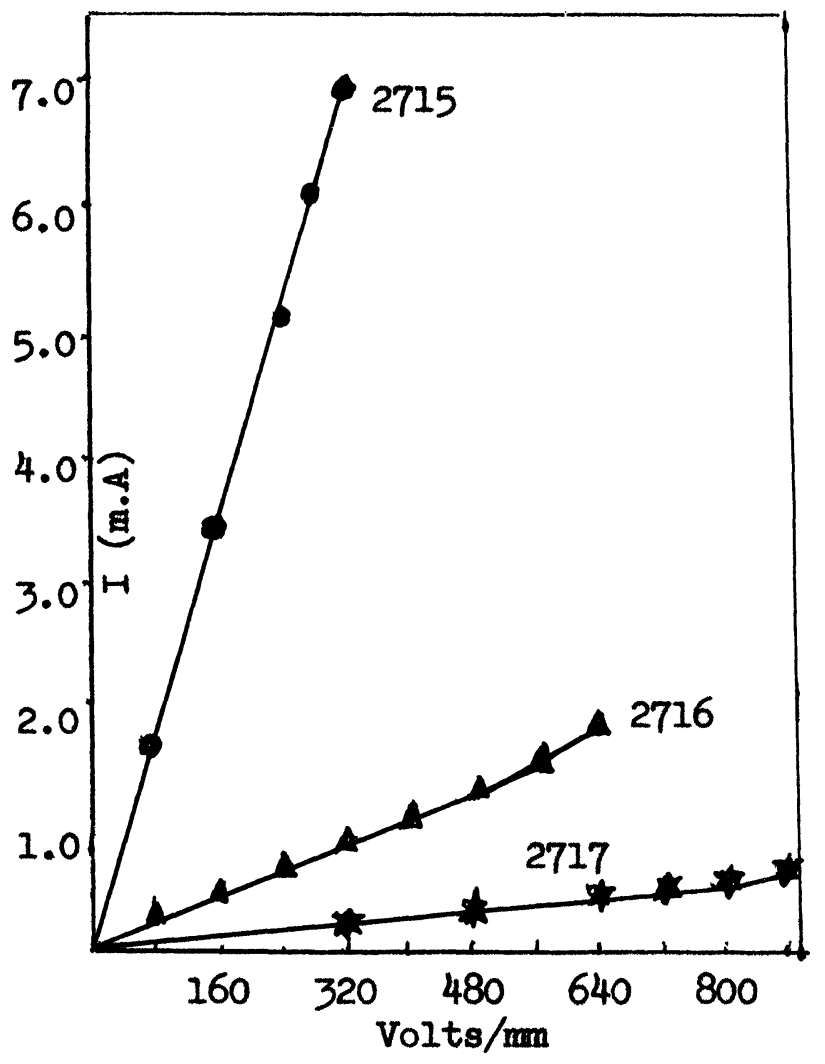

FIGURE 10 Current vs. voltage. containing very high $\mathrm{Ag}$ content. These geometry effects can be minimized by faster firing cycles.

Figure 7 shows the variation of TCR $(+25$ to $+125^{\circ} \mathrm{C}$ ) as a function of resistor length with $\mathrm{Pd} / \mathrm{Ag}$ terminations. As can be seen the TCR becomes more positive for the shorter resistors. This is attributed to the $\mathrm{Ag}$ diffusion effect.

\section{VCR EFFECTS}

The voltage coefficient of resistance (VCR) was measured between V2 and V1 where V2 is 10 times greater than V1. For the $1 \mathrm{Mohm}$ per square resistor $80 \mathrm{~V}$ and $8 \mathrm{~V}$ were used. VCR measurements are plotted as a function of resistor length in Figure 8 for the 2716 composition. VCR values drop sharply and approach a common limiting value for long resistors, which is largely independent of the termination. Much larger differences are seen between conductors with short lengths. VCR's for resistors are believed to be due to combined effects of contact resistance and the characteristics of the

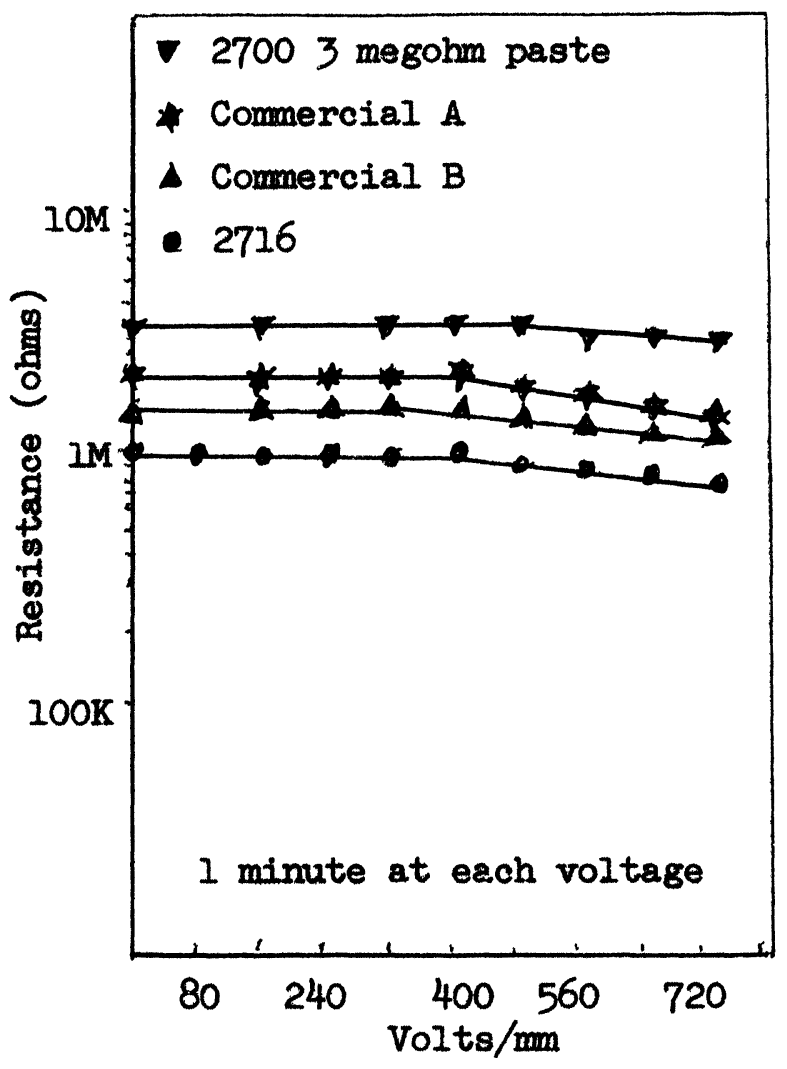

FIGURE 11 Resistance vs. voltage. 
resistor structure. As length increases, the intrinsic resistor properties become dominant, and VCR per unit length apparently approaches a limiting asymptotic value. The small residual differences between the 3 curves which are still observed even for $4 \mathrm{~mm}$ long resistors may represent real contact region effects. The $10 \mathrm{Mohm}$ per square and $100 \mathrm{kohm}$ per square curves are not included but follow the same trend. Limiting values of VCR observed were 10 to $15 \mathrm{ppm} / \mathrm{V} / \mathrm{cm}$ for the 2717,5 to $10 \mathrm{ppm} / \mathrm{V} / \mathrm{cm}$ for the 2716 , and 0 to $5 \mathrm{ppm} / \mathrm{V} / \mathrm{cm}$ for the 2715 compositions.

VCR's of this Series have also been examined as a function of peak firing temperature between $825^{\circ} \mathrm{C}$ and $875^{\circ} \mathrm{C}$ and with variations of firing times ranging between 22 and 60 minutes at $850^{\circ} \mathrm{C}$. No significant differences were detected in VCR within these sets of firing conditions.

\section{POWER LOADING}

Figure 9 shows the average temperature rise of resistors to which power was applied. The resistors were all 1.56 square $\mathrm{mm}$ in area fired on $0.67 \mathrm{~mm}$ thick alumina (96\%) substrates. The resistors were located in a row $7 \mathrm{~mm}$ from the substrate edge. The method of measurement involved placing fine particles of sharply melting crystalline compounds or alloys on the surface of the resistors then gradually increasing the applied voltage. At each voltage, 1 minute was allowed for the system to reach thermal equilibrium. For a single $100 \mathrm{~K} \mathrm{ohm}$ resistor approximately 1.8 watts $/ \mathrm{mm}^{2}$ was needed to melt an alloy at a temperature of $138^{\circ} \mathrm{C}$. When 2 or 3 resistors placed in a row $2.5 \mathrm{~mm}$ center to center distance apart were simultaneously loaded, the power per resistor needed to reach a given temperature is, of course, significantly decreased. It is estimated that approximately $2.0,1.0$, and 0.5 watts $/ \mathrm{mm}^{2}$ are required to raise the temperature to $150^{\circ} \mathrm{C}$ for 1,2 and 3 resistors respectively. Resistor areas and layout densities must be carefully calculated so as not to exceed either the wattage rating for individual resistors or the maximum hot spot temperature. We suggest that a maximum hot spot temperature of $150^{\circ} \mathrm{C}$ be used in determining safe power loading for most thick film resistors.

The amount of power applied should not be allowed to raise the temperature beyond this level for $1 \%$ tolerance resistors. Power should thus be derated to zero whenever the ambient temperature plus the applied power cause the temperature to reach $150^{\circ} \mathrm{C}$.
By means of curves such as those in Figure 9 based on the amount of resistor area in use on a substrate, proper safe limits to applied power can be determined. Heat stabilization pretreatments may be used if higher power loading or smaller design tolerances than $1 \%$ are desired. Stabilizations between 200 and $500^{\circ} \mathrm{C}$ have been used to lower resistance changes to less than $0.1 \%$ after 1000 hours at $150^{\circ} \mathrm{C}$. If only a few small resistors are widely spaced on a substrate, power loadings as high as 0.5 to 1.0 watts $/ \mathrm{mm}^{2}$ may be used. Through the use of $\mathrm{BeO}$ substrates or good thermal dissipation packaging, power levels can be raised by more than a factor of 10 .

\section{HIGH VOLTAGE PROPERTIES}

Figure 10 shows the current versus voltage behavior of these resistors. Voltage is applied sequentially for 1 minute at each voltage. The resistors are $1.25 \mathrm{x}$ $1.25 \mathrm{~mm}$ long with $P d / A g$ terminations. Corrections due to heating effects are not made in these plots. The resistors show an ohmic characteristic up to 900 volts $/ \mathrm{mm}$ for the $10 \mathrm{Mohm}$ per square

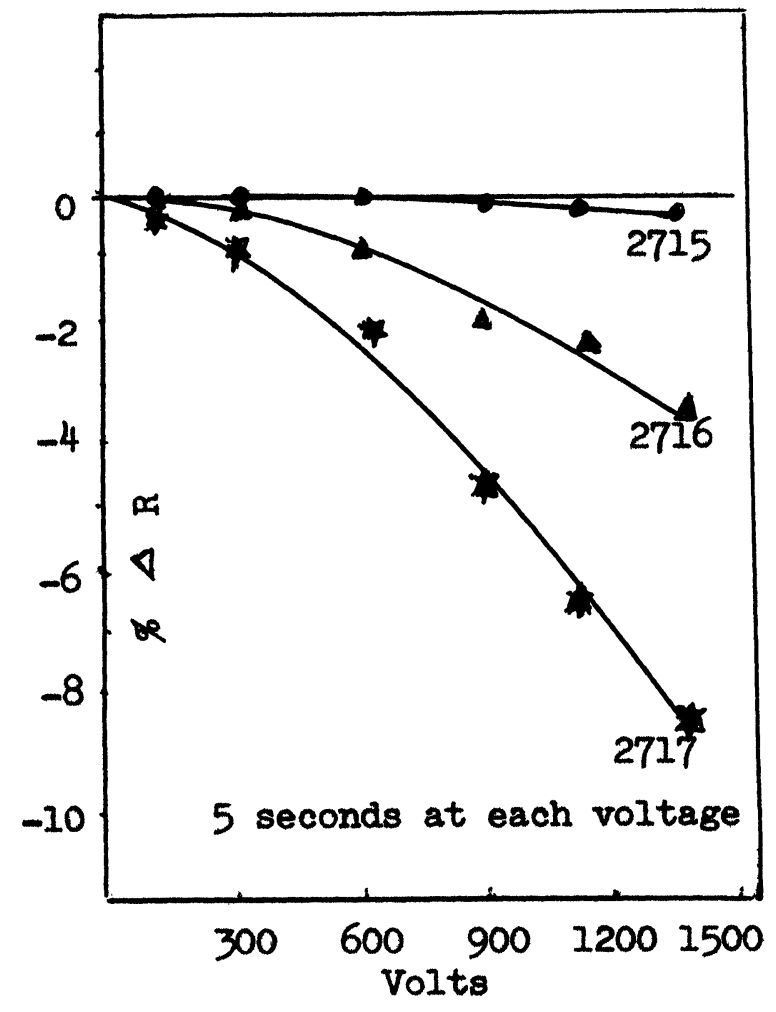

FIGURE 12 Voltage step stress seq. 


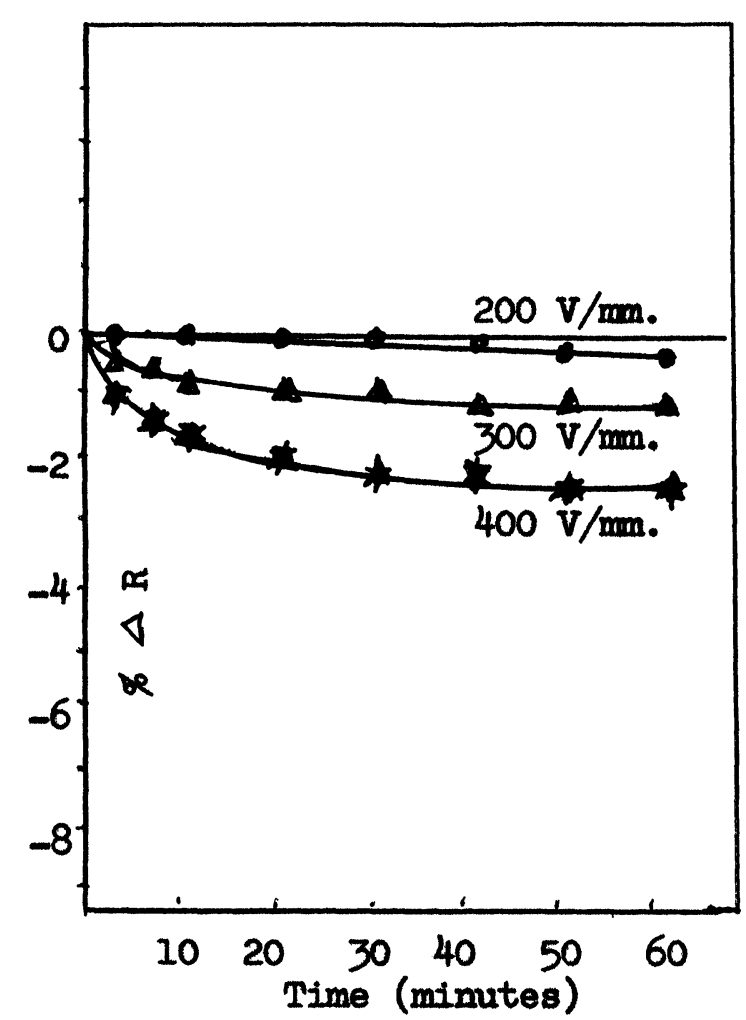

FIGURE 13 Voltage stress vs. time.

composition and up to more than 400 volts $/ \mathrm{mm}$ for the $1 \mathrm{Mohm}$ material. The $100 \mathrm{kohm}$ per square curve is linear up to its maximum power rating. A comparison of 2700 Series with several commercial voltage resistor systems is shown in Figure 11, which plots resistivity vs. volts $/ \mathrm{mm}$. Commercial resistor $A(2 \mathrm{Mohm})$ and 2716 were linear to
400 volts $/ \mathrm{mm}$. The $(2700) 3 \mathrm{Mohm}$ paste remained linear to 500 volts $/ \mathrm{mm}$.

Figure 12 shows step stress test results. Increasing voltages are sequentially applied for 5 seconds and the resistance change at each level is measured. As may be expected, the higher the resistivity, the greater the negative change due to the increased role played by non-tunnelling barriers. The 2715 hardly changed even when 1200 volts are applied. By comparison, a similar valued resistor made from ESL 2815 Series fails catastrophically at 600 volts.

Figure 13 shows the effect of high voltage as a function of time on a $1 \mathrm{Mohm}$ resistor. Curves are shown for the application of 4,6 and $8 \mathrm{kV}$ across a resistor $2 \mathrm{~cm}$ long for 1 hour. The resistors are allowed to heat up and no liquid coolant or heat sinking is used. Changes in resistance occur rapidly and most of the negative resistance changes are completed with 5 minutes. These changes are believed to be due to breakdown of non-tunnelling barriers. The higher the applied voltage, the greater will be the number of barriers converted to more ohmic contacts.

The 2700 Series exhibits good homogeneity and uniformity throughout its cross-section as well as on the resistor surface. Wiping spring contacts are feasible for high voltage potentiometer uses. Resistivities up to $1 \mathrm{Mohm}$-per square have CRV values below $2 \%$, and have application for use in TV focus potentiometers.

Table I summarizes some of the characteristic performance levels. The system is relatively insensitive to humidity, heat, shock and voltage stresses. Laser trimming experiments have been carried out using an ESI Model 20, Q switched YAG

TABLE I

ESL \#2700, typical properties

\begin{tabular}{ll}
\hline 1. TCR & $\pm 300 \mathrm{ppm} /{ }^{\circ} \mathrm{C}$ \\
2. TCR Tracking $\left(-55\right.$ to $\left.+125^{\circ} \mathrm{C}\right)$ & $<10 \mathrm{ppm} /{ }^{\circ} \mathrm{C}$ \\
3. Voltage Rating & $3 \mathrm{kV} / \mathrm{cm}$ \\
4. Wattage Rating & 0.5 to $1.0 \mathrm{watt} / \mathrm{mm}^{2}$ \\
$\begin{array}{l}\text { (Do not exceed } 150^{\circ} \mathrm{C} \text { hot } \\
\text { spot temperature) }\end{array}$ & $\left(300\right.$ to $\left.600 \mathrm{watts} / \mathrm{in}^{2}\right)$ \\
5. Thermal Stability & \\
$200^{\circ} \mathrm{C}, 500$ hours & $<0.5 \% \Delta R$ \\
$450^{\circ} \mathrm{C}, 200$ hours & -2 to $-4 \% \Delta R$ \\
6. Humidity (100\% R.H., $\left.95^{\circ} \mathrm{C}\right)$ & $<0.10 \% \Delta R$ \\
120 hours & $<0.2 \% \Delta R$ \\
7. Stability to Solder Dip & $100 \mathrm{kohm} / \mathrm{sq} .-0.05 \% \Delta R$ \\
(10 seconds at $\left.220^{\circ} \mathrm{C}\right)$ & $1 \mathrm{Mohm} / \mathrm{sq} .-0.5 \% \Delta R$ \\
8. 100 Capacitor Discharge Pulses & $10 \mathrm{Mohm} / \mathrm{sq} .-3.1 \% \Delta R$ \\
(1 kV/mm in free air) & $\Delta u$ Terminations
\end{tabular}


laser. Adjustments have been in the form of " $L$ " shaped cuts made at $2.25 \mathrm{kHZ}, 2.5 \mathrm{~mm} / \mathrm{sec}$. using 2 watts (I $=19 \mathrm{amps})$ of average power. Drift after trimming was measured at various time intervals up to 1000 hours. Changes averaged below $0.3 \%$.

\section{CONCLUSIONS}

Studies of conduction mechanisms in thick film resistors have led to the introduction of high resistivity 2700 Series. These resistors are based on a ruthenium-compound semiconducting phase dispersed in a carefully selected and compatable glassy matrix. The conducting networks present in the structure include ohmic, non-ohmic and insulating barriers. High electric fields and, to some extent, thermal interactions shift the relative concentrations of these types of barriers by converting increasing numbers of insulating barriers into semiconducting or conducting ones. Electric field breakdown of insulating barriers increases as voltage is increased. Resistance changes which result are always negative, since more network pathways are created. If formulations are designed to minimize the number and participation of insulating barriers, more uniform network structures consisting mainly of metal-semiconductor junctions are formed. The dielectric breakdown effects will be less dominant in determining the overall characteristics of the resistor. Changes caused by voltage include both reversible and irreversible component portions. The reduction in the magnitude of irreversible changes of a resistor is a measure of the efficiency achieved in forming networks with relatively few non-tunnelling barriers. Further studies aimed at extending the improved metal-semiconducting behavior of these materials to even higher ohmic values are planned. Examination of the "trade-offs" between thermal and electrical stability, TCR, noise and related characteristics is continuing.

\section{REFERENCES}

1. L. K. H. Van Beek, in Progress in Dielectrics, Vol. 7, p. 69, Heywood, London (1965).

2. J. C. Wimmer, H. C. Graham and N. M. Tallan, in Electrical Conductivity in Ceramics and Glass, N. M. Tallan, ed., Part B, p. 619, Marcel Dekker, New York (1974).

3. R. E. Meredith and C. W. Tobias, in Advances in Electrochemistry and Electrochemical Engineering, P. Delahey and C. W. Tobias, eds., Vol. 2, p. 15, Interscience, New York (1962).

4. P. A. Lightsey, Phys. Rev., B8, 3586 (1973).

5. V. Awbegaokar, S. Cochran and J. Kurkijarvi, Phys. Rev., B8, 3682 (1973).

6. I. Webman and J. Jortner, Phys. Rev., B11, 2885 (1975).

7. R. M. Scarisbrick, J. Phys., Di Appl. Phys., 6, 2098 (1973).

8. R. W. Vest, Final Technical Report, (Purdue Research Foundation) Purdue University, Dec. 1975.

9. G. E. Pike and C. H. Seager, Proc. 1976 Int. Microelectronics Symposium, Vancouver, B.C. p. 213 (ISHM, P.O. Box 3255, Montgomery, Alabama, 36109).

10. C. H. Seager and G. E. Pike, Proc. 1976 Int. Microelectronics Symposium, Vancouver, B.C., p. 115 (ISHM, Montgomery, Alabama).

11. P. W. Polinski, Proc. 1973 Electronic Components Conference, Washington, D.C., p. 153.

12. A. Olivei, Proc. 1973 Electronic Components Conference, Washington, D.C., p. 140.

13. P. F. Curcia, S. E. Champ, R. B. Flippen, 1976 Electronic Components Conference, San Francisco, CA. p. 156.

14. Y. Taketa and M. Haradome, IEEE Trans. on Parts, Hybrids and Packaging, PHP-10, 74 (1974).

15. Y. Taketa and M. Haradome, Proc. 1972 Int. Microelectronic Symposium, Washington, D.C. 

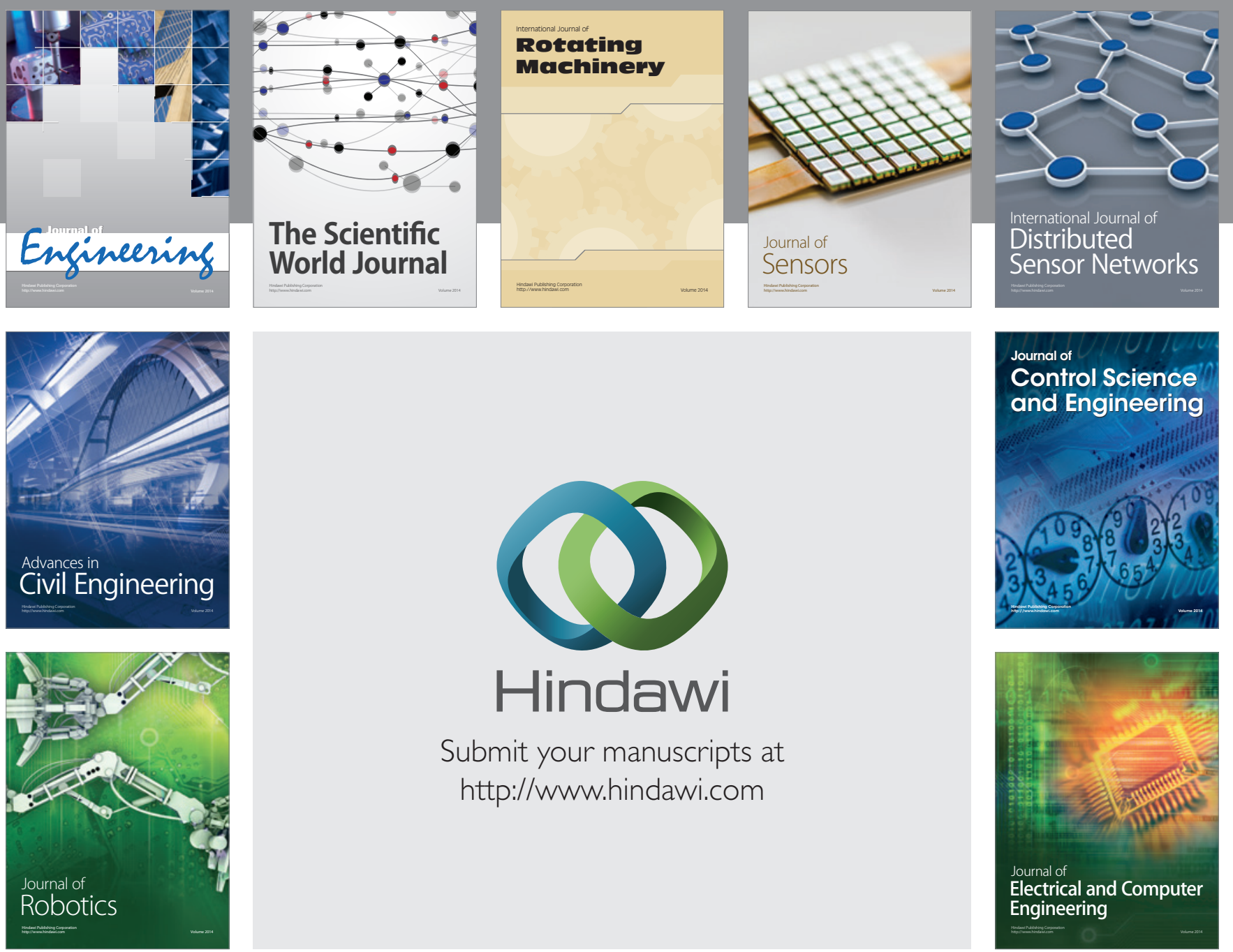

Submit your manuscripts at

http://www.hindawi.com
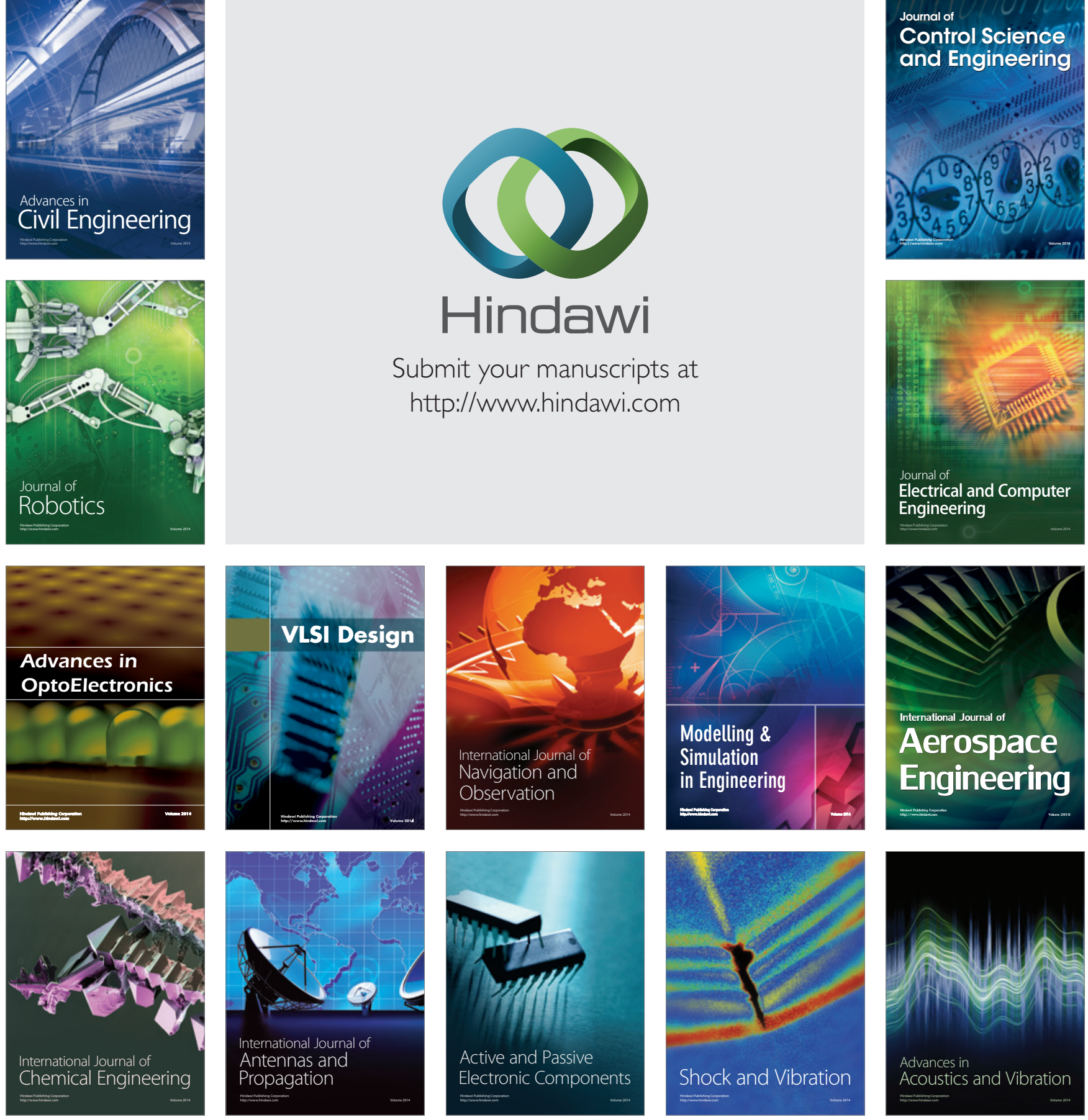